\title{
Mikroenkapsulasi Antosianin Kulit Buah Kakao (Theobroma cacao L.) Dengan Metode Koaservasi Kompleks
}

\author{
(Microencapsulation of Anthocyanine of Kakao (Theobroma cacao L.) Bark with Complex \\ Coaservation)
}

\author{
Siska Syahfitri Lubis, Evi Sulastri, Muhammad Sulaiman Zubair \\ Program Studi Farmasi, Fakultas MIPA, Universitas Tadulako, Palu-Sulawesi Tengah, 94118
}

Article Info:

Received: 12 Agustus 2018

in revised form: 02 September 2018

Accepted: 10 September 2018

Available Online: 01 October 2018

Keywords:

Microencapsulation

Anthocyanine

Kakao

Theobroma cacao

Complex Coaservation

Corresponding Author:

Evi Sulastri

Program Studi Farmasi

Universitas Tadulako

Palu 94118

Evisulas3@gmail.com

\begin{abstract}
Anthocyanin is a class of antioxidants that are widely found in the skin of cocoa fruit (Theobroma cacao L.). Anthocyanin degradation occurs not only during the extraction process from plant tissues but also during the storage process. The microencapsulation process can protect the active substance from environmental influences or improve the stability of the preparation. This study aims to characterize anthocyanin microcapsules from cocoa (Theobroma cacao L.) fruit peel using a complex coacervation method, therefore, it can provide economic value added from this plant. Anthocyanin microencapsulation was formulated using a coating of gelatin: arabic gom with different concentrations of 1:1, 3:2, and 2:1. Microcapsule characterization was organoleptic and morphological test, particle size distribution, moisture content test, absorption efficiency, recovery test, antioxidant activity of the preparation, and FTIR analysis. The results showed that extract yield was 39.82\%, optimum microcapsule characterization was obtained from 1: 1 concentration with $36.65 \%$ recovery test, $80.40 \%$ absorption efficiency, and antioxidant activity with $I_{50}$ of 20.52 ppm.
\end{abstract}

Copyright (C) 2017 JFG-UNTAD

This open access article is distributed under a Creative Commons Attribution (CC-BY-NC-SA) 4.0 International license.

How to cite (APA 6th Style):

Lubis, S.S., et al. (2018). Mikroenkapsulasi Antosianin Kulit Buah Kakao (Theobroma cacao L.) dengan Metode Koaservasi Kompleks. Jurnal Farmasi Galenika: Galenika Journal of Pharmacy, 4(2), $106-112$. doi:10.22487/j24428744.2018.v4.i2.11077 


\begin{abstract}
ABSTRAK
Antosianin merupakan golongan antioksidan yang banyak terdapat pada kulit buah kakao (Theobroma cacao L.). Degradasi antosianin terjadi tidak hanya selama proses ekstraksi dari jaringan tumbuhan tetapi juga selama proses penyimpanan. Proses mikroenkapsulasi dapat melindungi zat aktif dari pengaruh lingkungan atau meningkatkan stabilitas sediaan. Penelitian ini bertujuan untuk melakukan karakterisasi sediaan mikrokapsul antosianin dari kulit buah kakao (Theobroma cacao L.) dengan metode koaservasi kompleks, sehingga dapat memberikan nilai tambah secara ekonomis dari tanaman tersebut. Mikroenkapsulasi antosianin diformulasi menggunakan penyalut gelatin-gom arab dengan perbedaan konsentrasi 1:1,3:2,2:1. Karakterisasi mikrokapsul adalah uji organoleptis dan morfologi, distribusi ukuran partikel, Uji kadar air, Efesiensi penjerapan,Uji perolehan kembali, aktivitas antioksidan sediaan, Analisis FTIR. Hasil penelitian menunjukkan rendamen ekstrak 39,82\%, karakterisasi mikrokapsul yang optimum diperoleh dari konsentrasi 1:1 dengan Uji perolehan kembali 36,65\%, Efesiensi penjerapan 80,40\%, dan aktivitas antioksidan dengan nilai $\mathrm{IC}_{50} 20,52 \mathrm{ppm}$.
\end{abstract}

Kata kunci : Antosianin, Kulit buah kakao, Mikroenkapsulasi

\section{PENDAHULUAN}

Buah kakao (Theobroma cacao L.) merupakan salah satu tanaman perkebunan yang telah banyak dibudidayakan diberbagai daerah di Indonesia. Data Statistik Perkebunan Indonesia tahun 2014-2016, menyebutkan bahwa produksi buah kakao tertinggi di hasilkan oleh provinsi Sulawesi Tengah dengan jumlah produksi 161.467 ton dengan luas area 291.445 Ha. Namun, dalam pengolahan buah kakao (Theobroma cacao L.) menjadi cokelat, bagian yang dimanfaatkan hanyalah keping bijinya saja, sedangkan kulit buahnya dibuang. Kulit buah kakao (Theobroma cacao L.) beratnya mencapai 75\% dari seluruh berat buah, sehingga dapat dikatakan bahwa limbah utama dalam pengelolahan buah kakao (Theobroma cacao L.) adalah kulit buah (Supriyanto, 1990). Tanaman kakao (Theobroma cacao L.) mengandung senyawa antioksidan dan antiradikal yang telah diuji secara invitro, beberapa dari senyawa fenolik tersebut yaitu katekin, epikatekin, antosianidin, proantosianidin, asam fenolik, dan beberapa flavonoid lainnya (Arlorio et al., 2005). Kulit kakao (Theobroma cacao L.) mempunyai potensi sebagai bahan antioksidan alami yang berfungsi memodulasi sistem imun, efek kemopreventif untuk pencegahan penyakit jantung koroner dan kanker.

Antosianin merupakan golongan antioksidan yang banyak terdapat pada kulit buah kakao (Theobroma cacao L.) yang terikat dengan glukosa (Figueira,
Janick, \& BeMiller, 1993). Degradasi antosianin terjadi tidak hanya selama ekstraksi dari jaringan tumbuhan tetapi juga selama proses penyimpanan. Ketidakstabilan antosianin dipengaruhi oleh beberapa faktor antara lain, $\mathrm{pH}$, temperatur, cahaya dan oksigen serta faktor lainnya seperti ion logam (Niendyah, 2004). Proses mikroenkapsulasi dapat melindungi zat aktif dari pengaruh lingkungan atau meningkatkan stabilitas sediaan (Aschida, Adhitiyawarman, \& Destiarti, 2014).

Dari metode-metode yang dipakai dalam pembuatan mikrokapsul, koaservasi kompleks adalah metode yang paling awal ditemukan dan telah diaplikasikan secara luas, proses koaservasi kompleks merupakan suatu metode pembuatan mikrokapsul dengan memanfaatkan sifat makromolekul yang mengandung senyawa kation dan anion untuk berinteraksi secara elektrostatik membentuk kapsul (Yeo, Bellas, Firestone, Langer, \& Kohane, 2005). Gelatin dan gom arab dipilih sebagai penyalut sebab keduanya merupakan makromolekul yang larut air sehingga lebih mudah dalam pembentukan mikrokapsul. Selain itu, baik gelatin maupun gom arab sama-sama merupakan biopolimer yang tidak berbahaya karena tergolong biopolimer generally recognized as safe (GRAS), tersedia melimpah di alam dan keduanya umum digunakan pada penelitian enkapsulasi dengan metode koaservasi kompleks (Qv, Zeng, \& Jiang, 2011). Siow \& Ong (2013) telah melakukan penelitian pembuatan mikrokapsul antioksidan minyak bawang putih dengan metode koaservasi 
kompleks menghasilkan mikrokapsul tertinggi dengan karakteristik yaitu untuk gelatin tipe A -gom arab (pH 4,5, rasio gelatin-gom arab 1:1, rasio bahan inti-bahan penyalut 6:1) mikrokapsul yang dihasilkan 86,6\%, ekstrak terkapsulkan 98,6\%, ukuran partikel 101,6 mikrometer, gelatin tipe B-gom arab $(\mathrm{pH} 3,5$, rasio gelatin-gom arab $1: 1$, rasio bahan inti-bahan penyalut 6:1) mikrokapsul yang dihasilkan $85,0 \%$, ekstrak terkapsulkan 96,2\%, ukuran partikel 94,5 mikrometer.

Berdasarkan uraian diatas, maka pada penelitian ini akan dilakukan pengembangan formulasi antosianin dari kulit buah kakao (Theobroma cacao L.) dalam bentuk sediaan mikrokapsul dengan menggunakan metode koaservasi kompleks. Selanjutnya dilakukan pengujian karakteristik mikrokapsul yang meliputi Uji organoleptik, pemeriksaan morfologi mikrokapsul, ukuran partikel mikrokapsul, Uji Perolehan Kembali (UPK), penetapan kadar air, efesiensi penjerapan mikrokapsul, Uji aktivitas antioksidan mikrokapsul, dan Analisis FTIR.

\section{METODE PENELITIAN \\ Alat dan Bahan}

Alat-alat yang digunakan pada penelitian ini adalah, wadah maserasi, rotary vacum evaporator, neraca analitik,hot plate,termometer, digital stirrer, oven, mikroskop cahaya, SEM (Scanning Electronic Microscopy), spektrofotometerFourier Transform Infrared (FT-IR), spektrofotometer UV-Vis, pH meter, deksikator, dan peralatan gelas lainnya yang umum digunakan dalam laboratorium.

Bahan-bahan yang digunakan dalam penelitian ini adalah kulit buah kakao (Theobroma cacao L.), Asam sitrat, Etanol p.a, DPPH, Asam asetat, $\mathrm{NaOH}$, $\mathrm{HCl}, \mathrm{KBr}$, gelatin, Gom arab, minyak jagung, Glutaraldehid, aquadest, $\mathrm{KCl}$, natrium asetat.

\section{Persiapan simplisia}

Buah kakao (Theobroma cacao L.) yang telah matang (kulit buah berwarna kuning kejinggaan dan biji sudah dapat diolah menjadi coklat) dipetik secara manual. Buah kakao segar yang telah dipetik kemudian dipotong secara melintang dan dikeluarkan bijinya menggunakan tangan. Selanjutnya kulit buah kakao (Theobroma cacao L.) (meliputi bagian epikarpium, mesokarpium dan endokarpium) dipotong-potong kecil, dan dikeringkandengan cara diangin-anginkan pada suhu ruang. Potongan tersebut lalu dihaluskan dengan blender hingga diperoleh serbuk simplisia kulit buah kakao.

\section{Ekstraksi}

Metode ekstraksi dilakukan mengikuti metode Simanjuntak, Sinaga, \& Fatimah, (2014), 600 g simplisia dimaserasi menggunakan pelarut Aquadest dan Asam sitrat 10\%. Aquadest merupakan larutan netral yang dapat melarutkan pigmen antosianin karena antosianin adalah senyawa yang larut dalam pelarut polar dan sifat pigmen antosianin umumna bersifat asam dan lebih stabil dalam kondisi asam. Perbandingan volume pelarut yang digunakan1:6 sebanyak $1200 \mathrm{ml}$ dengan lama ekstraksi 3 hari pada suhu ruang, kemudian disaring dan filtratnya ditampung. Filtrat yang diperoleh diuapkan dengan rotary evaporatorpada suhu $40^{\circ}$ C sehingga didapatkan ekstrak kental.Ekstrak yang didapatkan disimpan dalam wadah yang terhindar dari cahaya dan dimasukkan kedalam freezer pada suhu $\pm 5^{\circ} \mathrm{C}$.

\section{Uji identifikasi antosianin}

Identifikasi antosianin dapat dilakukan dengan cara melakukan analisisi kualitatif dengan menggunakan pengujian pewarnaan menambahkan $\mathrm{HCl} 2 \mathrm{M}$ pada sampel kemudian dipanaskan selama 5 menit, apabila sampel tetap berwarna merah maka sampel positif mengandung antosianin (Harbone, 1987).

\section{Uji aktivitas antioksian ekstrak antosianin}

Ditimbang 1.9716 mg DPPH, masukkan dalam labu ukur $10 \mathrm{ml}$ kemudian ditambahkandengan etanol pro analisis dan kocok. Sebanyak 10 ml larutan DPPH induk, dimasukkan ke dalam labu ukur lalu ditambahkan etanol pro analisis hingga $50 \mathrm{ml}$. Dipipet $5 \mathrm{ml}$ larutan blanko, kemudian dihomogenkan dan dibiarkan selama 30 menit selanjutnya diukur serapannya pada panjang gelombang 517.Diambil 10mg ekstrak kulit buah naga super merah. Lalu dimasukkan ke dalam labu ukur dan ditambahkan etanol pro analisis hingga 10 $\mathrm{ml}$, sehingga diperoleh konsentrasi $1000 \mathrm{ppm}$. Selanjutnya lakukan pengenceran dengan cara dipipet $0,5 \mathrm{ml}, 0,4 \mathrm{ml}, 0,3 \mathrm{ml}, 0,2 \mathrm{ml}, 0,1 \mathrm{ml}$, dan 0,05 mldari larutan induk sampel. Lalu masing-masing dimasukkan ke dalam labu ukur $10 \mathrm{ml}$ dan ditambahkan dengan etanol pro analisis sehingga diperoleh konsentrasi 100 ppm, 80 ppm, 60 ppm, 40 ppm, 20 ppm, dan 10 ppm.Selanjutnya dipipet 2,5 ml dari masing-masing konsentrasi lalu masukkan ke dalam tabung reaksi dan ditambahkan dengan 2,5 ml larutan DPPH blanko. Kemudian didiamkan selama 
30 menit dan diukur absorbansinya pada panjang gelombang $517 \mathrm{~nm}$.

\section{Formulasi Mikrokapsul}

Pembuatan mikrokapsul dilakukan mengikuti metode Siow \& Ong (2013) dengan beberapa modifikasi sebagai berikut: Ekstrak dan minyak jagung dicampurkan terlebih dahulu selanjutnya ditambahkan emulgator tween 80. Dibuat Gelatin tipe A konsentrasi $(1 \%, 1,3 \%, 1,2 \%$ w/v) dan gom arab konsentrasi $(1 \%, 0,7 \%, 0,8 \% \mathrm{w} / \mathrm{v})$ masing-masing dengan cara dilarutkan dengan aquadestpada suhu $40^{\circ} \mathrm{C}$ dalam waterbath. Selanjutnya ekstrak diemulsikan kedalam larutan gelatin tipe A konsentrasi $(1 \%, 1,3 \%, 1,2 \% \mathrm{w} / \mathrm{v})$ menggunakan digital stirrer dengan kecepatan 200 rpm selama 30 menit. Selanjutnya ditambahkan gom arab konsentrasi $(1 \%, 0,7 \%, 0,8 \% \mathrm{w} / \mathrm{v})$ secara bertahap untuk menghasilkan bobot biopolymer 2 gram dengan volume akhir $200 \mathrm{ml}$. Pengadukan terus dilakukan dengan kecepatan 200 rpm menggunakan digital stirrer pada suhu $40^{\circ} \mathrm{C}$ selama 30 menit. Selanjutnya atur $\mathrm{pH}$ dengan menambahkan larutan asam asetat $10 \% \mathrm{v} / \mathrm{v}$ hingga didapat $\mathrm{pH} 3,5$ untuk membentuk koasevasi kompleks. Selanjutnya campuran didinginkan pada suhu $5^{0} \mathrm{C}$ sambil diaduk dengan kecepatan 200 rpm. Larutan Glutaraldehid (2 $\mathrm{ml} / 280$ g) ditambahkan kedalam campuran selanjutnya campuran ditambahkan $\mathrm{NaOH} 20 \%$ w/v hingga didapat $\mathrm{pH} 9$ untuk mengeraskan dinding penyalut. Campuran diaduk dengan kecepatan 200 rpm selama 60 menit. Pengadukan dihentikan sampai terbentuk lapisan koaservat diatas campuran. Lapisan koaservat dicuci dengan $50 \mathrm{ml}$ Aquadest dingin dan disaring dengan pompa vacum menggunakan kertas Whatman No.1. Tahap pencucian dihentikan sampai filtrat diperoleh. Mikrokapsul dikeringkan dengan cara kering beku. Selanjutnya mikrokapsul disimpan dalam desikator untuk mengurangi kelembaban sampai bobot konstan diperoleh. Kemudian dilakukan Karakterisasi mikrokapsul berupa uji organoleptik, efesiensi penjerapan, Uji perolehan kembali, uji kadar air, distribusi ukuran partikel, morfologi mikrokapsul, analisis FTIR.

\section{HASIL DAN PEMBAHASAN}

\section{Pembuatan Ekstrak Kulit Buah Kakao (Theobroma cacao. L).}

Hasil ekstrak kental kulit buah kakao yaitu 119,46 gram, dengan persen rendamen sebesar 39,82\%.

\section{Hasil uji identifikasi antosianin}

Hasil dari pengujian warna dari ekstrak kulit buah kakao yaitu positif warna tetap merah. Hasil dapat dilihat pada (Gambar 1) dibawah ini.

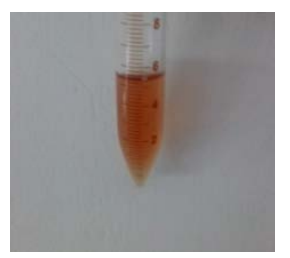

Gambar 1. Hasil identifikasi antosianin

\section{Pengujian aktivitas antioksidan ekstrak}

Pengujian aktivitas antioksidan ekstrak kulit buah kakao diperoleh nilai $\mathrm{IC}_{50}=20.52 \mu \mathrm{g} / \mathrm{mL}$ dari nilai $\mathrm{IC}_{50}$ yang diperoleh dinyatakan bahwa ekstrak kulit buah kakao memiliki aktivitas antioksidan yang sangat kuat. Suatu senyawa dikatakan antioksidan sangat kuat jika nilai IC 50 kurang dari $50 \mu \mathrm{g} / \mathrm{mL}$ (Leiwakabessy, 2011).

\section{Karakterisasi mikrokapsul Uji Organoleptik}

Hasil pemeriksaan organoleptis mikrokapsul yang dihasilkan dari metode koaservasi kompleks dari formula I (1:1) berupa serbuk cokelat gelap, berbau minyak, formula II (3:2) berupa serbuk cokelat kemerahan, berbau minyak, dan formula III (2:1) berupa cokelat gelap, berbau minyak. Hasil pengujian organoleptis dapat dilihat pada (Gambar 2)

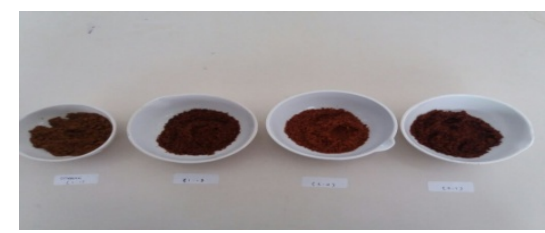

Gambar 2. Hasil organoleptik

\section{Efesiensi penjerapan}

Hasil efesiensi penjerapan mikrokapsul yang diperoleh dari formula I (1:1) $80.40 \% \pm 8.87$, formula II (3:2) $17,01 \% \pm 9.72$, formula III $(2: 1) 51,06 \% \pm$ 28.62.Efesiensi penjerapan belum mencapai $100 \%$ dapat disebabkan karena banyak hal, salah satu faktor yang dapat menyebabkan adalah senyawa yang berdifusi keluar melalui pori yang terbentuk pada dinding mikrokapsul saat pencucian.

\section{Uji perolehan kembali}

Hasil pengujian perolehan kembali yang diperoleh pada formula I (1:1) 36.65\%, formula II (3:2) 
36.35\%, dan formula III (2:1) 43.05\%. Semakin besar konsentrasi penyalut yang digunakan maka semakin besar uji perolehan kembali yang dihasilkan. Uji perolehan kembali yang dihasilkan tidak sesuai, hal ini disebabkan karena dalam proses pembuatan mikrokapsul hilangnya koaesrvat dapat disebabkan pada saat melakukan adjust $\mathrm{pH}$, dan menempelnya koaservat pada kertas saring dan wadah pada saat memisahkan koaservat dengan fase air.

\section{Kadar air}

Kadar ekstrak yang digunakan adalah 8,41\%, kadar air penyalut gelatin $7,49 \%$ gom arab $13,51 \%$, dan kadar air mikrokapsul untuk formul I (1:1) 3,69\% \pm SD 0,254 , formula II (3:2) 4,61\% \pm SD 0,192 formula III (2:1) 4,77\% \pm SD 0,190. Perbedaan kadar air yang diperoleh dapat dipengaruhi oleh kadar air zat aktif ataupun penyalut yang digunakan. Semakin banyak jumlah penyalut yang digunakan maka meningkat pula kadar air yang diperoleh (Febriyenti, Ben, \& Prima 2013).

\section{Distribusi Ukuran partikel}

Hasil pengukuran distribusi ukuran partikel mikrokapsul yang diperoleh pada formula I (1:1) $18.38388 \mu \mathrm{m}$, formula II (3:2) $25.13576 \mu \mathrm{m}$, formula III (2:1) $27.01747 \mu \mathrm{m}$. Menurut Madene, Jacquot, Scher, \& Desobry, (2006) ukuran partikel dengan metode koaservasi kompleks adalah 5-200 $\mu \mathrm{m}$.

\section{Morfologi mikrokapsul}

Hasil morfologi mikrokapsul dilakukan menggunakan alat SEM (Scanning Electron Microscope). Berdasarkan hasil pengamatan morfologi mikrokapsul formula I (1:1) berbentuk bulat tidak sempurna (sferis) dengan permukaan sedikit berpori, formula II (3:2) berbentuk sferis dengan permukaan berpori, formula III (2:1) berbentuk sferis dengan permukaan berpori. Hal ini sesuai dengan penelitian Kamala (2010) mikrokapenkapsulasi vitamin A dengan penyalut gelatin-gom arab, mikrokapsul ang dihasilkan berbentuk sferis.

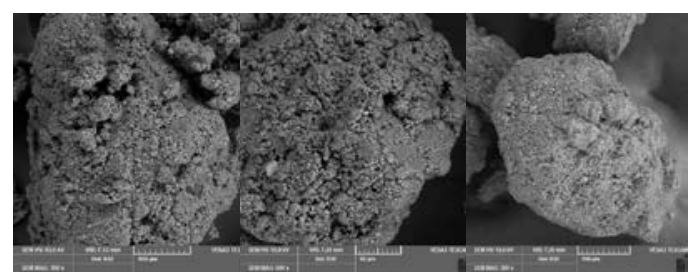

a.

b.

c.

Gambar 3. Hasil SEM Mikrokapsul. a. Mikrokapsul 1:1, b. Mikrokapsul 3:2, c. Mikrokapsul 2:1

\section{Analisis FTIR}

Hasil analisis spektrum inframerah pada (Gambar 1 ekstrak kulit buah cokelat) memperlihatkan adanya senyawa antosianin dibuktikan dengan adanya gugus C-O-C pada peak $1234,44 \mathrm{~cm}^{-1}$, -C-NO $\mathrm{NO}_{2}$ pada peak $1419,61 \mathrm{~cm}^{-1}, \mathrm{C}=\mathrm{C}$ pada peak 1635,64 $\mathrm{cm}^{-1}$, C-OH pada peak 1732,08 $\mathrm{cm}^{-1}$, CH pada peak 2929,87 $\mathrm{cm}^{-1}$. Hasil FTIR dapat dilihat pada (Gambar 4) dibawah.

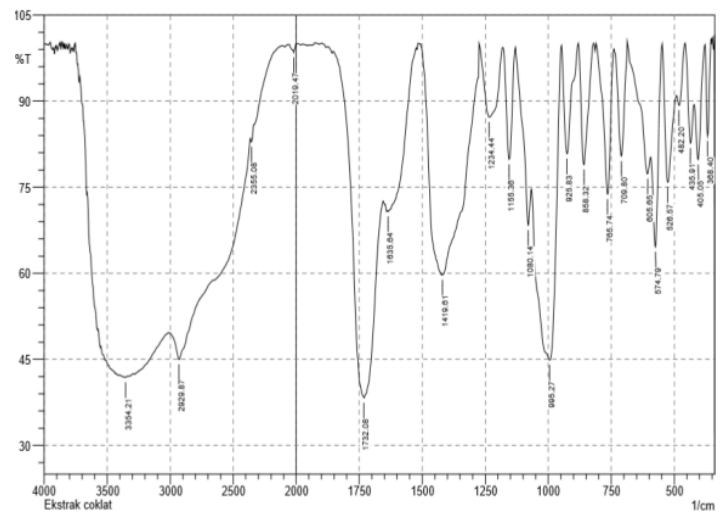

Gambar 4. Spektrum FTIR ekstrak kulit buah cokelat

Hasil analisis spektrum inframerah pada (Gambar 2 Mikrokapsul 1:1) memperlihatkan adanya penyalut gelatin dibuktikan dengan gugus $\mathrm{NH}$ amina sekunder dan primer pada peak 3450,65 $\mathrm{cm}^{-1}$, amina N-H(b) pada peak $1589,34 \mathrm{~cm}^{-1}$. Identifikasi penyalut gom arab dibuktikan dengan adanya gugus $\mathrm{CH}$ pada peak $2942,09 \mathrm{~cm}^{-1}$, terdapatb gugus karbohidrat pada peak $844,82 \mathrm{~cm}^{-1}$ sampai peak 1193,94 $\mathrm{cm}^{-1}$. Identifikasi senyawa antosianin dibuktikan dengan adanya gugus aldehida pada peak $2854,65 \mathrm{~cm}^{-1}$, gugus $\mathrm{C}=\mathrm{C}$ pada peak $1633,71 \mathrm{~cm}^{-1}$, gugus $-\mathrm{N}=\mathrm{N}$ - pada peak 1589,34 $\mathrm{cm}^{-1}$, gugus $-\mathrm{C}-\mathrm{NO}_{2}$ pada peak $1305,81 \mathrm{~cm}^{-1}$ sampai $1417,68 \mathrm{~cm}^{-1}$ (Gambar 5).

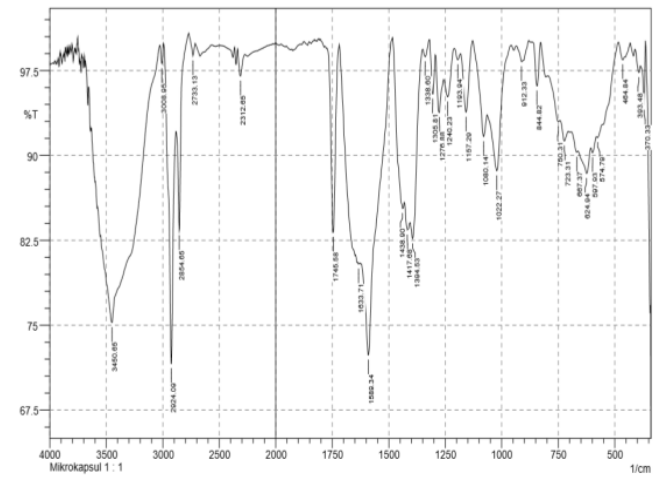

Gambar 5. Spektrum FTIR Mikrokapsul 1:1

Hasil analisis spektrum inframerah pada (Gambar 2 Mikrokapsul 3:2) memperlihatkaan adanya penyalut 
gelatin dibuktikan dengan gugus $\mathrm{NH}$ amina sekunder dan primer pada peak 3450,65 $\mathrm{cm}^{-1}$, amida pada peak 3290,56 $\mathrm{cm}^{-1}$. Identifikasi penyalut gom arab dibuktikan dengan adanya gugus $\mathrm{CH}$ pada peak $2926,01 \mathrm{~cm}^{-1}$, gugus $\mathrm{OH}$ pada peak 3558,67 $\mathrm{cm}^{-1}$, gugus karbohidrat pada peak 844,82-1159,22 $\mathrm{cm}^{-}$ ${ }^{1}$.Identifikasi senyawa antosianin dibuktikan dengan adanya gugus aldehida pada peak 2854,65 $\mathrm{cm}^{-1}$, gugus $\mathrm{C}=\mathrm{C}$ pada peak $1624,06 \mathrm{~cm}^{-1}$, gugus $\mathrm{CO}$ pada peak $1554,63 \mathrm{~cm}^{-1}$, gugus -C-NO $\mathrm{NO}_{2}$ pada peak $305,81-$ $1480 \mathrm{~cm}^{-1}$, gugus C-O-C pada peak $1240,23 \mathrm{~cm}^{-1}$. Hasil FTIR dapat dilihat pada gambar 6.

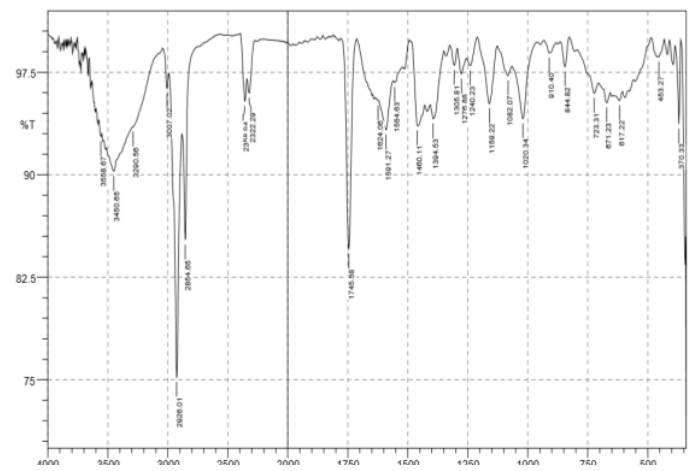

Gambar 6. Spektrum FTIR Mikrokapsul 3:2

Hasil analisis spektrum inframerah pada (Gambar 2 Mikrokapsul 2:1) memperlihatkaan adanya penyalut gelatin dibuktikan dengan adanya gugus amina sekunder dan primer $\mathrm{NH}$ pada peak $3452,58 \mathrm{~cm}^{-1}$, gugus amida $\mathrm{NH}$ pada peak $3284,77 \mathrm{~cm}^{-1}$, gugus amina $\mathrm{N}-\mathrm{H}(\mathrm{b})$ pada peak $1589,34 \mathrm{~cm}^{-1}$. Identifikasi penyalut gom arab dibuktikan dengan adanya gugus CH pada peak 2926,01 $\mathrm{cm}^{-1}$, gugus karbohidrat pada peak 844,82-1190,08 $\mathrm{cm}^{-1}$. Identifikasi senyawa antosianin dibuktikan dengan adanya gugus C-O-C pada peak1242,16 $\mathrm{cm}^{-1}$, gugus $-\mathrm{C}-\mathrm{NO}_{2}$ pada peak 1305,81-1436,97 $\mathrm{cm}^{-1}$. Hasil FTIR dapat dilihat pada gambar 7.

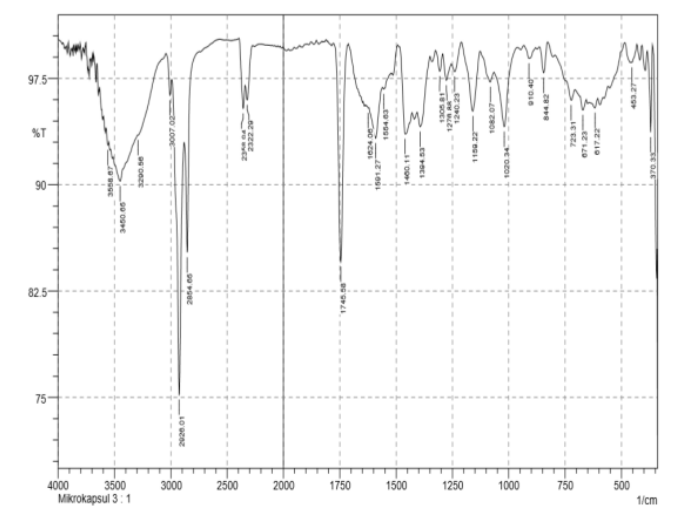

Gambar 7. Spektrum FTIR Mikrokapsul 2:1
Hasil FTIR pada ekstrak dan mikrokapsul sesuai dengan penelitian sebelumnya yaitu hasil identifikasi dengan spektrofotometer FTIR, antosianin memiliki gugus $\mathrm{O}-\mathrm{H}, \mathrm{CH} 2, \mathrm{C}=\mathrm{O}$ karbonil, $\mathrm{C}=\mathrm{C}$ aromatik, =C$\mathrm{H}$ aromatik, C-O-C eter, C-O alkohol dan substitusi benzena yang memperkuat hasil analisis spektroskopi UV-Vis yang menandakan adanya gugus aromatik, $\mathrm{OH}$, serta $\mathrm{C}=\mathrm{O}$ karbonil, hasil identifikasi gelatin dengan spektrofotometer FTIR adalah gugus amida A (3270-3370 $\mathrm{cm}^{-1}$ ), amida B $2947 \mathrm{~cm}^{-1}, \mathrm{C}=\mathrm{O} 1637 \mathrm{~cm}^{-}$ 1, hasil identifikasi gom arab dengan spektrofotometer FTIR adalah gugus $\mathrm{OH}, \mathrm{CH}$, COO,dan karbohidrat (Ibekwe, Oyatogun, Esan, \& Oluwasegun, 2017; Lestari, Kusrini, \& Anam, 2014).

\section{Uji aktivitas antioksidan mikrokapsul}

Hasil aktivitas antioksidan mikrokapsul antosianin dengan nilai $\mathrm{IC}_{50}$ pada formula I (1:1) 20,52 ppm, formula II (3:2) 32,1 ppm, formula III (2:1) 30,56 ppm dari nilai $\mathrm{IC}_{50}$ yang diperoleh dinyatakan bahwa ekstrak kulit buah kakao memiliki aktivitas antioksidan yang sangat kuat. Suatu senyawa dikatakan antioksidan sangat kuat jika nilai IC 50 kurang dari 50 g/mL (Leiwakabessy, 2011).

\section{KESIMPULAN}

Karakterisasi mikrokapsul yang optimum dihasilkan oleh mikrokapsul perbandingan 1:1 dengan hasil Uji perolehan kembali 36,65\%, Efesiensi penjerapan 80,40\%, Uji kadar air 3,69\%, distribusi ukuran partikel $18.38388 \mu \mathrm{m}$, aktivitas antioksidan sangat kuat dengan nilai $\mathrm{IC}_{50} 20,52 \mathrm{ppm}$.

\section{UCAPAN TERIMAKASIH}

Terima kasih penulis ucapkan kepada kanda Istigfarin dan Iyam Santoso atas bantuannya selama melaksanakan penelitian ini

\section{DAFTAR PUSTAKA}

Arlorio, M., Coïsson, J. D., Travaglia, F., Varsaldi, F., Miglio, G., Lombardi, G., \& Martelli, A. (2005). Antioxidant and biological activity of phenolic pigments from Theobroma cacao hulls extracted with supercritical CO 2. Food Research International, 38, 1009-1014.

Aschida, C. J., Adhitiyawarman, \& Destiarti, L. (2014). Enkapsulasi dan Uji Stabilitas Pigmen Karotenoid dari Buah Tomat yang Tersalut Carboxy Methyl Cellulose (CMC). JKK, 3(2), 44-49. 
Febriyenti, Ben E.S., Prima T., (2013). Formulasi Mikrokapsul Glikuidon Menggunakan Penyalut Etil Selulosa Dengan Metode Emulsifikasi Penguapan Pelarut. Fakultas Farmasi Universitas Andalas, Padang.

Figueira, A., Janick, J., BeMiller, J.N. (1993). New products from Theobroma cacao: Seed pulp and pod gum. p. 475-478. In: J. Janick and J.E. Simon (eds.), New crops. Wiley, New York

Harborne, J.B. (1987). Metode Fitokimia Penuntun Cara Modern Menganalisa Tumbuhan, Terjemahan K. Padmawinata Edisi II. Bandung: ITB Press.

Ibekwe, C. A., Oyatogun, G. M., Esan, T. A., \& Oluwasegun, K. M. (2017). Synthesis and Characterization of Chitosan / Gum Arabic Nanoparticles for Bone Regeneration. American Journal of Materials Science and Engineering, 5(1), 28-36.

Kamala, N. (2010). Mikroenkapsulasi Vitamin A Palmitat Dengan Menggunakan Gelatin Akasia Secara Koaservasi Kompleks. Skripsi. Universitas Indonesia. Depok.

Leiwakabessy, J. (2011). Komposisi Kimia dan Identifikasi Senyawa Antioksidan dari Ekstrak Tambelo (Bactronophorus Thoracites) (Master's thesis, Sekolah Pascasarjana Institut Pertanian Bogor, 2011). Bogor: Institut Pertanian Bogor.

Lestari, P. P., Kusrini, D., \& Anam, K. (2014). Anthocyanin Identification of Methanol-HCl Extract Active Fraction in Rosella ( Hibiscus Sabdariffa . L ) and Its Potential as Xanthine Oxidase Inhibitor. Jurnal Sains Dan Matematika, 22(3), 72-78.

Madene, A., Jacquot, M., Scher, J., \& Desobry, S. (2006). Flavour encapsulation and controlled release - a review. International Journal of Food Science and Technology, 41, 1-21.
Niendyah, H. (2004). Efektivitas Jenis Pelarut dan Bentuk Pigmen Antosianin Bunga Kana (Canna coccinea mill.) Serta Aplikasinya pada Produk Pangan. Skripsi. Universitas Brawijaya, Malang.

Qv, X., Zeng, Z., \& Jiang, J. (2011). Preparation of lutein microencapsulation by complex coacervation method and its physicochemical properties and stability. Food Hydrocolloids, 25(6), 1596-1603.

Simanjuntak, L., Sinaga, C., \& Fatimah. (2014). Ekstraksi Pigmen Antosianin dari Kulit Buah Naga Merah (Hylocereus Polyrhizus). Jurnal Teknik Kimia, 3(2), 25-29.

Siow, L., \& Ong, C. (2013). Effect of pH on Garlic Oil Encapsulation by Complex Coacervation. Journal of Food Processing \& Technology, 4(1), 1-5.

Supriyanto. (1990). Karakteristik Tepung Kulit Buah Coklat. Yogyakarta: Laporan Penelitian Fakultas Teknologi Pertanian UGM.

Yeo, Y., Bellas, E., Firestone, W., Langer, R., \& Kohane, D. S. (2005). Complex Coacervates for Thermally Sensitive Controlled Release of Flavor Compounds. Journal of Agricultural and Food Chemistry, 53, 75187525. 